\title{
Introduction to the Handbook on Migration and Welfare: The contours of contested concepts Markus M. L. Crepaz
}

The nexus between migration and welfare has hardly ever been more salient than now. On their own, migration and welfare, broadly conceived, have been core themes in the academic fields of political science, international affairs, sociology, economics, and public administration for decades. However, only since the beginning of the new millennium has there been a systematic focus on the many intriguing ways these two central policy fields interact with each other. Scholarly activity has grown exponentially since then and vibrant scholarly debates ensued. However, very little consensus has been achieved and much remains contested. This Handbook collects the leading theoretical and empirical contributions based on the central questions and approaches to the field resulting in a stimulating collection of the current state of the art in this diverse field.

Given the scant scholarly agreements in the complex relationships between migration and welfare, it might be prudent to reflect on the dictum of the eminent physicist Werner Heisenberg that "we have to remember that what we observe is not nature in itself, but nature exposed to our method of questioning". In the social sciences, as opposed to the natural sciences, results differ not only on the "method of questioning", such as whether scholars use quantitative or qualitative approaches - both of which are represented in this Handbook - but also on the particular field of study that examines the interactions between migration and welfare. As a result, I endeavored to give voice to a variety of disciplines, such as political science, sociology, economics and economic history, human geography, political psychology as well as political philosophy. Moreover, I purposefully solicited chapters representing a wide range of age and reputation of contributors. A number of chapters are written or co-authored by some of the most prominent, senior scholars in the field while others are crafted by up-and-coming, junior colleagues. Finally, I also attempted to achieve gender parity as much as possible. Almost half of the chapters (45 percent) in this Handbook are either authored or co-authored by female scholars.

While I attempted to inject diversity in terms of methods, fields, seniority, and gender, I was specific in terms of the task I posed to the contributors. First, I charged the contributors with establishing the state of the art of this research field by reviewing what we know, what we think we know, and what the future contours of research might look like. Readers of this volume are provided with an authoritative summary of the state of play in this tension-filled relationship between migration and welfare.

Second, the contributors were tasked with developing original theoretical but testable hypotheses and/or empirical contributions to push the frontier of our current knowledge. In the most general terms, the central question posed to the contributors in the first four parts of the book is this: will the publics in western societies want to continue funding the welfare state if they perceive, correctly or not, that some of their taxes are going to migrants who look differently, dress differently, speak differently, believe in a different 


\section{Handbook on migration and welfare}

god in addition to a multitude of other visible and behavioral differences, than the native borns? This question was intentionally posed as broadly as possible in order to allow a variety of explanations to flourish. Unsurprisingly, the answers proffered give rise to new questions in turn: does it make a difference how generous the welfare is? Do varying levels of solidarity and trust affect the way native borns are willing to share with migrants? Are political institutions simply a reflection of the migration context or are they actively shaping it? The old question of "do parties matter" comes into play also. Does it matter which parties are in power in terms of how the tension between migration and welfare is resolved, or not? Could the extent to which specific social rights that are extended to migrants mediate the way native borns are more or less willing to share? Do multiculturalism policies engender more tolerance with newcomers or does it lead to the development of "parallel societies"? Fundamentally, at an individual level, how does an individual's education and cultural capital affect the relationship between "them" and "us"? Do native borns react differently in terms of their willingness to disentitle migrants from welfare benefits as a function of whether they are labor migrants or asylum seekers? For those who champion progressive policies an even more profound question presents itself: is it possible to have both, a generous social welfare state and liberal immigration policies? Fortunately, these and many other questions have been either competently answered or at least richly illuminated in this Handbook.

The questions raised in the fifth part of the book deal with a much neglected, yet crucial element of migration and welfare, namely the effect of migration on sending countries. There is a vibrant debate among those who conceive of migration as a development strategy insofar as the erstwhile migrants remit significant monies and ideas to their home countries while others consider these remittances as sources of rising economic and ethnic inequality. Do such remittances absolve governments in the Global South to pursue meaningful, lasting development strategies? What is the role of ethnic diasporas abroad and do their social and economic remittances affect some ethnic groups more than others in their homeland? Is the claim that migration as a development strategy is nothing but a form of neo-liberal globalization in disguise? What would a counter-hegemonic or "southern perspective" of development look like? Would global migration regimes be necessary to establish more equity between workers in the Global North and South?

After the introduction, the 26 chapters in the Handbook are divided into five parts which are deliberately titled in broad terms. This introduction will provide very brief summaries of each contribution followed by reflections on where there are differences and similarities between the various chapters.

In Part I of the Handbook Pieter Bevelander and James Hollifield explore the degree to which immigration poses a threat to the welfare state in comparison with other purported threats to its viability in addition to providing a succinct overview of the problematique of this policy field. They argue that immigration generates specific policy challenges to welfare states on account of their claimed ethos of equal treatment and social equality for all legal residents. Finding that while there is tremendous variation in which different countries have employed different strategies to deal with the migration challenge, what appears to be key to successful immigration outcomes are earnest integration policies and the granting of rights to migrants. Nevertheless, more generous welfare states do seem to attract particularly asylum seekers and refugees which turn out to be more difficult to integrate. Whether they represent a particular fiscal burden on the welfare state depends 
on their age, education level, and the social capital of migrants. Ultimately, whether welfare states can sustain high levels of immigration is a function of political constellations, institutional contexts, and the historical reach of systemic racist and nativist legacies.

Maureen Eger concludes that while there is little evidence that economic issues might undermine the viability of welfare states, the same may not be true for political challenges. Setting the stage by providing a sweeping review of the relevant literature, she highlights various mechanisms that account for the negative association between immigration and welfare state support. The concept of reciprocity is crucial in altruistic concepts such as a redistributive welfare state. However, when native borns believe that out-groups either do not pay taxes or abuse the social welfare system, they might feel less inclined to pay their fair share, thereby undermining the viability of the welfare state. Her empirical analysis across 24 European countries at two time periods (2002 and 2014) indicates that on average, people believe that immigrants are a net burden on welfare states. Other mechanisms, such as in-group bias, or whether native borns consider immigrants as competitors for scarce resources, similarly indicate that people's sentiments tend to favor either disentitling migrants for social benefits, to impose harsher immigration controls, or to reduce redistribution in general. According to Eger, it is natives' attitudes towards migrants and beliefs about their effects on the social cohesion that drives the political challenges to the welfare state.

Noting that much of the public opinion/attitudes-related research has reached a "stalemate", Patrick Ireland laments that the burgeoning welfare-migration cottage industry has generated very few clear answers. He implores readers to go beyond attitudes and to examine not just policy outputs but real-world outcomes. In his view, the causal chain that most quantitative researchers explore stops one link too short, namely at the level of popular attitudes towards redistribution assuming, perhaps erroneously, that attitudes drive actual levels of social benefits. Instead, he argues, scholars should go one more link further, examining how attitudes are connected to actual social spending and benefit levels. However, even social spending is ultimately only a policy output, and still not a policy outcome which is yet one more link removed. In the end, what determines how migrants fare is a matter of the amount and quality of health care, education, and labor market integration they receive, among others. In his words, what matters for migrants is "how welfare delivery truly operates in diversifying societies". To uncover this would require more qualitative approaches, according to Ireland.

Part II of the book raises one of the central questions in the relationship between migration and welfare, namely: why share with strangers, or more specifically: is social homogeneity a precondition for redistribution? Matthew Wright lays out a variety of perspectives based on what human nature is believed to be. He finds that the willingness to share with others depends on whether one takes a view that humans are rational utility maximizers or whether people possess a broader sense of belonging to particular groups with its attendant emphasis on social identity. Sharing, according to Wright, occurs more easily if members of the group share a sense of identity based on either ethnic, national, or racial categories. A yet different perspective is contained in a "values" approach that is centered on a concept of fairness based on norms which have congealed into contractually agreed relationships. This view differs from the group-centered approach insofar as it is not so much about whether immigrants are part of one's group but whether they 


\section{Handbook on migration and welfare}

adhere to broadly accepted social norms. These perspectives, however, appear rarely in their pure form and occur most often in hybrid manifestations.

Allison Harell, Will Kymlicka, and Keith Banting examine the criteria as to who deserves to be included in social benefits and argue for deservingness criteria that are grounded in more than just "civic" and "ethnic" conceptions. Instead, they argue that it is "membership perceptions" upon which natives decide the boundaries of support for redistribution by which they mean the degree to which natives consider immigrants to be willing and committed members of the community. This perception goes beyond just simply conceiving of immigrants as contributors in an economic sense or as sharing the social norms of the host society, as Wright argued above, but whether natives see immigrants as deserving of social benefits based on their beliefs that immigrants are committed members of the community. An empirical analysis indicates that Canada shows a particularly strong association between membership perceptions and inclusive redistribution.

While Wright and Harell et al. examine these issues from a politico-theoretical perspective, Elie Murard and Anthony Kevins were tasked with providing an empirical examination as to whether a redistributive welfare state is compatible with liberal immigration policies. Murard, borrowing from his co-authored, forthcoming work with the late Alberto Alesina and Hillel Rapoport, finds that local exposure to immigration reduces native citizens' support for redistribution. This association is based on a novel dataset consisting of 140 regions across 16 European countries. Murard's finding of course does not mean that the actual size of the welfare state will diminish - rather, reduced public welfare support as a result of exposure to immigration might manifest itself in the rise of anti-immigrant parties, in a systematic disentitling of migrants from social benefits, and even in a rightward shift of the whole party system in a country. While this would not engender the viability of the welfare state per se, it would draw harsher borders between "us" and "them" in terms of who is eligible for protection from the vagaries of the market.

Anthony Kevins argues that immigration might have different effects on the welfare state depending on the type of welfare program, such as whether it is means tested, insurance based, or based on universal benefits. He zeroes in on an item in the 2016 European Social Survey which tapped public support for a universal basic income scheme. Kevins finds that those countries with a higher stock of immigrants show lower support for a universal basic income scheme. However, that relationship only applied to lower-educated individuals suggesting that attitudes are not set in stone and are constantly shaped via socialization, education, and interactions with other members of the community.

Edward Koning focuses on welfare chauvinism which is the argument that social benefits should only accrue to the "rightful" members of the community, based either on ethnic, or national, membership and suggests that opposition to immigrants' access to social programs can be driven by two very different positions: a neo-liberal position which argues that any social programs are inimical to the efficient functioning of capitalist markets and thus should either be abolished or significantly reduced, and a welfare chauvinist position. At the surface, if not conceptually and empirically separated, these two positions are observationally equivalent and, thus, can lead to a number of measurement errors, six of which Koning highlights in his conclusions. Intriguingly, Koning finds, similarly to Kevins, that low education drives welfare chauvinism, but not neo-liberal opposition to the welfare state. 
Conrad Ziller and Romana Careja employ a multilevel model using the two waves of the European Social Survey (2008 and 2016) and probe for the individual and contextual correlates of welfare chauvinism. Consistent with the findings by Koning and Kevins, they also find that lower-educated individuals are associated with higher levels of welfare chauvinism. Among other findings, and unsurprisingly, people who live comfortably on their current income show lower welfare chauvinism, while for people who are unemployed the opposite is true. Liberal integration policies, using the MIPEX integration policy measure, depress welfare chauvinism. The variable "proportion of immigrants", however, proved to be sensitive to the type of model specification employed.

Part III shifts the focus to the role of political institutions, broadly understood, and their effects on the migration and welfare nexus. In Part II, political institutions, regimes, and policies were largely argued to be simply bystanders in this push and pull of the migration and welfare vectors. In Part III the authors examine whether policies, types of migration, welfare regimes, political parties, and others can mediate the effects of migration on generalized trust, solidarity, or support for the welfare state more generally. Concepts such as trust and solidarity have become increasingly understood to play a crucial intermediary role between increasing immigration and the natives' willingness to entitle migrants to social benefits as these cultural features may be associated with political institutions, broadly conceived. This part of the Handbook hints at a potential for agency suggesting that perhaps multicultural and integration policies, equal or unequal access to social benefits, political parties of different hues, and other contextual factors may shape the migration and welfare context by being more or less adept in generating solidarity and trust between natives and newcomers and affect support for the welfare state more generally.

Anita Manatschal implores scholars to pay attention to what she calls the "indirect" effects of integration policies on native-born attitudes. These indirect effects, such as perceptions on the migrants' part that they are part of the broader society and that they have a stake in society, are a function of the degree to which integration policies extend socioeconomic, civic-political, and cultural rights to migrants. According to Manatschal, generously extending such rights could change the native borns' view of migrants as the "other" to a more inclusive view that sees migrants as part and parcel of society.

Staying with the question of whether policies can make a difference, Keith Banting, Daniel Westlake, and Will Kymlicka empirically examine whether multiculturalist policies weaken support for the welfare state based on newly extending their Multiculturalism Policy Index to 2020, thereby covering five time periods starting in 1980 in ten-year increments. Not only do they not find a reduction in multiculturalist policies, their empirical analysis indicates that both at the individual as well as the state level, there is a positive relationship between support for multiculturalist policies and support for the welfare state. Moreover, they find that multiculturalist policies are not associated with welfare chauvinist behavior. In their own words, "it is time to lay the ghost of the progressive's dilemma to rest".

Maureen Eger and Joakim Kulin, however, disinter that very specter by examining attitudes about immigration and redistribution and associate them with voting behavior for Sweden, the United States, and Germany, paragons of social democratic, liberal, and conservative welfare states. Based on pooled, cross-sectional data from the European Social Survey and the General Social Survey, they find that attitudes consistent with this 
dilemma have been present in these countries for a long time. While the authors find that progressive attitudes are on the increase in both Germany and the United States, they conclude that only those on the very left in terms of support for immigration and redistribution can be counted on to also vote for left-wing parties.

Zoe Lefkofridi and Susanne Rhein similarly focus on the fate of social democratic parties (SDPs) as they negotiate the tension between redistribution and immigration which they term the "social democratic dilemma". They borrow Peter Mair's conceptual difference between responsiveness and responsibility; the former of which suggests that parties follow the desires of their electorate while the latter means that parties need to honor agreements that they have signed. SDPs, they argue, located in European Union (EU) countries are particularly challenged because EU regulation impedes independent welfare state policy making, as they are losing control over redistribution, an issue they traditionally "owned". This EU-imposed neo-liberal turn makes it more difficult for SDPs to produce a coherent policy stance as far as the rights of migrants to social benefits are concerned. Lefkofridi and Rhein suggest that as long as there are no transnational policies governing redistributive policies, SDPs will be hamstrung in effectively answering the redistribution-immigration tension.

Elif Naz Kayran and Melanie Kolbe also examine the role of institutions broadly understood and focus on whether welfare state institutions can mitigate the widely argued corrosive impact of diversity on trust. Their empirical argument based on nine waves of the European Social Survey initially finds that as the stock of immigrants increases, generalized trust decreases. They then turn their attention to a recently developed measure by Edward Koning, entitled the "Immigrant Exclusion to Social Programs Index" (IESPI). This index measures differential access to social benefits between native borns and immigrants and can be conceived of capturing the variation in "inclusive" or "exclusive" solidarity prevalent across countries. When Kayran and Kolbe statistically interact their diversity measure (percent stock of migrants) with the IESPI, they find that when countries treat migrants more equally with respect to access to social benefits, the negative impact of diversity on trust is significantly reduced.

Are varying levels of inequality and labor market integration, which are themselves resultants of welfare state institutions, systematically associated with more or less support for the welfare state? Similarly, could it be that poor labor market integration of immigrants might have a negative impact on welfare state support? Christel Kesler draws on a variety of data sources such as the International Social Survey Program, the Luxembourg Income Study, and the World Bank's World Development Indicator Database, among others. Applying a pooled cross-sectional, time series model consisting of 20 countries and 54 country years with a total of over 69,000 individuals, she concludes that while overall income inequality measured by the GINI coefficient does not matter much, labor market integration of immigrants in the host country matters. As numbers of immigrants rise and unemployment inequality between immigrants and native borns widens, public support for the welfare state declines. However, where labor market integration of immigrants is successful, larger numbers of immigrants do not affect public support for the welfare state highlighting the crucial role of policies focusing on immigrant integration.

Frida Boräng, Sara Kalm, and Johannes Lindvall identify three challenges in the literature on the nexus between welfare and migration: first, they argue that the differences 
between labor migration, asylum and refugee policy, as well as immigrant policy are so consequential that they need to be studied on their own terms. Second, they call for a more historically oriented approach since, in their view, the welfare state has co-evolved with migration policy. Third, precisely because the welfare state and migration policy have developed in tandem, they argue, it makes no sense to claim causal connections between migration and the welfare state or vice versa. They provide evidence that while welfare state generosity and openness is positively related for asylum and refugees, the association between welfare state generosity and policy openness is orthogonal for labor migrants. A similar relationship exists when policy openness is plotted over time: after the Second World War policy openness increased for asylum seekers and refugees but declined dramatically for labor migrants, particularly after the mid-1970s. They also remind readers of the rarely achieved high standards of causal inference in empirical studies and make a plea for the relevance of qualitative, historical accounts.

Part IV investigates the effects of contact between native borns and migrants and political culture on the association between welfare and migration. Would it make a difference whether there is more or less meaningful contact between migrants and native borns or whether either one of them is more or less trusting of the "other"? Hanna Kleider confronts the question by taking a broad approach and exploring whether cultural or economic anxieties drive opposition to migration. Her exercise of theory generation borrows concepts from social psychology as she delves into this hotly contested dichotomy of potential explanations. After laying out arguments for the plausibility of both, economic as well as cultural determinants of anti-immigrant attitudes, she concludes that it might be time to move beyond this twofold approach and locates new areas of research such as the role of political parties and various forms of media and their capacity to frame immigrant and welfare issues. Media framing effects could even affect what would otherwise be believed to be "individual-level" characteristics, such as education and religiosity. Moreover, what might be considered "independent" cultural and economic effects might be resultants of how immigrants and their supposed threat are socially constructed by the media, political entrepreneurs, and anybody else with the capacity to leave a public trace.

Hans-Georg Betz focuses on nativism, and, taking a historic view, concludes that over long stretches of time economic and cultural threats have long been employed by various political parties and leaders to gin up anti-immigrant attitudes. However, he argues that more recently economic grievances among the native borns have increased as a function of globalization and modernization which generates a section of the populace without the wherewithal to compete in this neo-liberal, market-driven environment. Combined with the decline of left-wing parties to secure their survival, this precariat is increasingly attracted to radical right-wing parties and their attendant media outlets that give voice to their grievances. From there, it is but a small step to make migrants responsible for their plight. According to Betz, nativist attitudes are triggered by four emotions: fear, anger, resentment, and shame - all of which play a crucial role in how sections of the populace are mobilized to support radical right-wing parties.

In a broad sweep, Eric Uslaner examines whether contact with strangers matters. This aptly called "contact theory", despite appearing quite intuitive at first glance, turns out to be rather complex. It may be self-evident that if natives actually knew and interacted with immigrants, they may develop a better sense of their challenges as immigrants or just simply recognize that they share the same joys and fears as the native borns and thus 


\section{Handbook on migration and welfare}

become more acceptant of migrants. But, what type of contact is necessary to trust strangers? Is any contact sufficient, or does it require sustained and meaningful interactions on an equal basis? Could the type of neighborhood, integrated or segregated, affect the degree of stereotype and prejudice? It appears that when people live in integrated neighborhoods they show less ethnic and racial prejudice than otherwise. A venerable literature pioneered by Robert Putnam has argued that trust emerges when people share common interests, such as bowling. Uslaner, however, argues that sharing a common interest is not enough in trusting others; it may be sufficient to tolerate others, but just simply sharing a similar hobby does not mean that others are accepted as part of one's "moral community". Uslaner argues that trust is acquired early in life during the formative years of socialization and, once established, does not vary much in later phases of life. Examining the correlates of trust, he finds that having various forms of interactions with strangers, having friends of different race and ethnicity, or frequency with which in-group and out-group members meet does not increase generalized trust.

Katerina Manevska, Roderick Sluiter, and Agnes Akkerman delve more deeply into the concept of "meaningful contact" and identify the workplace as a locus where meaningful contact might occur given that such interactions depend heavily on interdependence and cooperation, in addition to potentially developing an esprit de corps as "colleagues" work towards a common goal. Manevska et al. find that where there are native workers with more interethnic resources, i.e. trust and belief in reciprocity in an out-group co-worker, this tends to morph into general trust for all members of that same ethnic out-group in addition to generating more ethnic tolerance. Intriguingly, a further finding is that workplace interethnic ties affect ethnic tolerance at the extremes of the scale: examining changes over time, for those low on prejudice and who already had outside work ties and for those high on prejudice without interethnic ties, having workplace interethnic ties increased ethnic tolerance. Their findings highlight the importance of focusing on workplace dynamics and its importance in shaping interethnic tolerance.

Patti Lenard investigates how bridging trust between native borns and migrants can be constructed and focuses on ways to shape inclusive forms of national identity. Rejecting the idea that there is something inherent or essential to national groups, she emphasizes the functions that individuals and institutions can play in constructing the boundaries of the identity and the groups that define its members. Two "levers" might increase trust among native borns: inclusive welfare state policies and multicultural policies both of which would signal that immigrants are welcome and that efforts are being made to integrate them into their newly chosen society. As a third lever she suggests national identity shaping, meaning that central governments have unique ways to generate trust in an increasingly diverse society assuming that this is what central governments want to do. This national identity shaping could be achieved in four ways: via public pronouncements and declarations, via shaping of naturalization requirements, via educational curricula, and via the construction/reconstruction of national symbols.

Arno Van Hootegem, Koen Abts, and Bart Meuleman are searching for the roots of solidarity in multicultural societies and compare majority as well as minority views (established minorities of Turks and Moroccans) on critiques of the welfare state in Belgium. They focus on moral, economic, and social criticism for institutional arrangements that redistribute towards vulnerable target populations. Comparing minority with majority views on the welfare state should allow them to determine whether these two 
groups have similar or different attitudes about the role of redistributive schemes - views that could be relevant for bridging trust across different ethnic communities. They find that minorities indicate lower social and moral criticism of the welfare state compared to majorities, which may be explained by their larger dependence on it. Majority groups, however, indicated stronger criticism along the dimensions of egalitarianism, authoritarianism, and left-right placement than the minority groups. This suggests that this type of criticism of the welfare state is more concerned with ensuring market efficiency and the maintenance of neo-liberal arrangements, while also capturing concerns that the welfare state breeds passivity and deviance.

Finally, Part V of the Handbook reverses the emphasis from the impact of immigration in receiving countries to the consequences of emigration in sending countries. Recent years have revealed the enormous size of remittances that sending countries have received, far outpacing official development assistance although most recently, remittances have dropped as a result of the Covid-19 pandemic. In addition, migrant diasporas affect sending countries not only via financial resources, but also social and ideological ideas. Farid Makhlouf and Oussama Ben Atta ask whether remittances support or undermine economic growth in the Global South. Their econometric model suggests that remittances, when low, do not positively affect economic growth as such remittances flow directly into consumption rather than investment. However, when remittances exceed a certain threshold, they do significantly affect economic growth in the Global South via investments with long-term, growth-inducing effects.

Mohammad Moniruzzaman and Margaret Walton-Roberts, in a qualitative case study of Bangladesh, find that migrant remittances contribute to higher household income and as a result increase food security. In addition, they find that remittances increase a household's dietary diversity, which tends to lag during economic shocks. Thus, not only do remittances ensure access to food, but also to foods of higher nutritional value which positively affects health outcomes more generally. Finally, remittances also affect food consumption, i.e. the quantity of food that is available, guarding households against food-related shocks and rationing.

Could migration be conceived of as a development strategy in more general terms? Elizabeth Mavroudi examines this complex question by reprising a large amount of literature concluding that migration can have both positive and negative impacts on development outcomes. She argues for a "people-centered" approach recognizing the personal, embodied endeavor that migration entails while at the same time calling for a liberal migration regime that allows for migrants to circulate, i.e. more freely to come and go so as to maximize the impacts of migration on development.

Raúl Delgado Wise critically assesses the migration-development nexus by questioning the, what he calls, "almost sacrosanct belief that migration contributes to the country of origin". He questions the neo-liberal, market-oriented migration policies and their supposed effects on development, and offers, among other contributions, a counter-hegemonic, southern development perspective based on a dialectical, rather than unidirectional, relationship between migration and development. Highlighting global inequality, the continuing unequal development between the Global North and South, human rights infringements of migrants in both the Global North and South, he calls for an international migration regime with the United States as a signatory which, alas, has not happened hitherto. Ultimately, according to Delgado Wise, it is critical to 
tackle the uneven power relationships between the Global North and South that characterize the world capitalist system, requiring a drastic rethink of the connections between development and migration with an attendant turn from a neo-liberal to a postliberal perspective.

\section{FROM SEEING TREES TO ENVISIONING FORESTS: IN SEARCH OF PATTERNS}

Reading these 26 outstanding contributions it is easy to miss the forest for the trees. What contours do emerge from this collection of chapters? Is it possible to identify patterns, similarities, and contradictions among the chapters? Looking for such patterns is a perilous endeavor, and this is not the place to exhaustively distinguish between agency, structures, cultures, institutions, policies, and methods of inquiry.

However, it appears that when migrants impinge on the welfare state, individually held attitudes, whatever they are, are not necessarily determinative of political outcomes. A number of chapters have highlighted the role of purposive agency in shaping such outcomes via multiculturalism policies and labor market integration policies, allowing more equal access to social benefits to migrants, and extending increased rights to migrants more generally. Such policies tend to bend the needle more towards broader acceptance of migrants than when they are absent.

Another pattern that emerges is the role of education. In a number of contributions, the socioeconomic status of individuals systematically affects their attitudes towards migrants. Specifically, higher-educated individuals tend to have more solidaristic attitudes vis à vis migrants than lower-educated ones. The reason may be that they are less exposed to resource competition from migrants or perhaps they are more sophisticated in giving socially desirable answers to queries tapping issues of nativism or xenophobia.

Structural constraints appear in the form of concerns that extending the fruits of the welfare state to migrants might undermine the efficient functioning of capitalist markets which may in some cases be mistaken as nativism or welfare chauvinism. When examining the impact of emigration on national development strategies, neo-liberal global economic policies are seen as the central obstacle to establishing fairer migration regimes. Constraints also appear in the form of the role the EU plays in restricting the extent to which member states can establish more or less generous welfare states.

Other contributions have zeroed in, some more directly than others, on the role of how politicians, political parties, and their associated media outlets frame the relationship between natives and migrants, suggesting that there is room for socially constructing and shaping this relationship. Such constructions can take various forms generating sentiments among natives ranging from perceiving that migrants are committed members of society to the generation of nativist attitudes. Echoing Heisenberg, that what we observe is a function of our method of questioning, a number of contributions plead for more qualitative, descriptive approaches to the nexus of migration and welfare on account of their conceptual complexity.

The prominent political scientist Karl Deutsch once remarked that "truth lies at the confluence of different streams of evidence", suggesting that when a variety of types of data, and measured at different levels, such as individual-level data, cross-national data, 
data collected over time, or even a combination, so-called pooled cross-sectional/time series data point in a similar direction, that the probability of an association between two variables increases. Despite measuring the "progressive's dilemma" with different data and measured at different levels, the relevant chapters in this Handbook indicate a lack of consensus as to whether it is possible to have a generous welfare state and liberal immigration policies at the same time. It appears that rumors of the death of the progressive's dilemma are exaggerated. Solving this conundrum with creative theoretical and empirical approaches will keep social scientists busy for the foreseeable future.

Finally, in addition to the factors laid out above, historical constraints such as whether natives believe theirs is a country of immigration or emigration and the long arc of a history of racism and nativism are likely to shape the degree to which native borns consider newcomers as part of their broader moral orbit and whether they are "worthy" receivers of social benefits. It is not set in stone that immigration and a generous welfare state are incompatible as this association is subject to ongoing political contestation. Whether native borns are willing and capable of transcending racial, ethnic, religious, and other differences is a function of their socioeconomic status, variations in institutions, of structural constraints, and the role of political entrepreneurs and their media outlets. Finally, it will require leadership and political will to craft policies to help native borns in recognizing migrants not as "others" but as part of their extended, moral community, but only if this corresponds to the wishes of the government and the people. 